\title{
CICATRIZAÇÃO CONDUZIDA E ENXERTO DE PELE PARCIAL NO TRATAMENTO DE FERIDAS
}

\author{
Mauro Ivan Salgado, Andy Petroianu*, Giselle lelis Burgarelli, Alfredo José Afonso Barbosa, luiz Ronaldo Alberti \\ Trabalho realizado no Departamento de Cirurgia da Faculdade de Medicina da Universidade Federal de Minas Gerais
}

*Correspondência: Av. Afonso Pena, 1626, apto. 1901

Belo Horizonte/MG

Cep: 30130-005

Tel/fax: (31) 3274-7744

petroian@medicina.ufmg.br

\begin{abstract}
RESUMO
Oвjetivo. Avaliar comparativamente os tratamentos para área cruenta da pele por meio de cicatrização conduzida (método original de cicatrização cutânea por segunda intenção) e enxerto de pele autógena.

Métodos. Foram utilizados 17 coelhos, dos quais foram retirados dois segmentos de pele, um de cada lado do dorso. De um lado, a área doadora do enxerto permaneceu cruenta, para cicatrização conduzida (A). Do outro lado do dorso, a pele foi implantada como enxerto (B), para recobrir a área cruenta. Assim, cada animal tinha em seu dorso os dois tipos de tratamentos (A e B). Os coelhos foram distribuídos em dois grupos, de acordo com o tamanho das feridas provocadas em seu dorso: grupo I - A e B $\left(4 \mathrm{~cm}^{2}\right)$ e grupo 2 - $A$ e $B\left(25 \mathrm{~cm}^{2}\right)$. Avaliou-se o tempo de cicatrização de ambos os tratamentos: grupo I, após 19 dias, e grupo 2, após 35 dias. Os aspectos macro e microscópico finais da cicatrização foram analisados comparativamente nos quatro subgrupos. À histologia, avaliaram-se o número e a espessura de estratos da epiderme, a presença de células inflamatórias, bem como de cistos epidérmicos e de células gigantes. O estudo estatístico usou os testes não paramétricos de Fischer, Kruskall-Wallis e Wilcoxon.
\end{abstract}

Resultados. Não se observou diferença macro ou microscópica entre a cicatrização conduzida e o enxerto de pele.

Conclusão. A cicatrização conduzida parece ser uma boa opção terapêutica para áreas cruentas cutâneas em coelhos.

Unitermos: Cicatrização de feridas. Transplante de pele. Desbridamento. Curativos.

\section{INTRODUÇÃO}

Em todas as civilizações, há relatos de tratamentos de feridas com o uso de curativos, bálsamos e retalhos, descritos em caracteres cuneiformes, em papiros, e por tradição oral ${ }^{1-3}$. A cicatrização de feridas, apesar de bem estudada, continua desafiando os pesquisadores. Processos cicatriciais podem ocorrer de diversas maneiras ${ }^{4-7}$ :

Processo cicatricial per si é a capacidade de o organismo reconstruir-se com cuidados de desbridamento $0^{8,9}$, limpeza e higiene local ${ }^{10,11}$. Esse processo divide-se em cicatrização por primeira intenção, que ocorre após o fechamento primário da ferida; e cicatrização por segunda intenção, que acontece quando a ferida fica aberta propositadamente, para fechamento espontâneo ou, em caso de deiscência, quando a ferida se abre mesmo após seu fechamento primário.

Uso de enxertos ou retalhos de pele, para abreviar o tempo de cura, evitando infecções e danos estéticos. Os enxertos livres de pele são secções do tegumento retiradas do local doador e transferidas para o leito receptor, onde recobrem a área cruenta e adquirem novo suprimento sangüíneo para manter a viabilidade das células transplantadas. Essas secções dermoepidérmicas podem conter ${ }^{12-15}$ :

I) Enxerto de pele parcial, a epiderme e parte da derme. Conforme a espessura da camada de derme usada é classificado como fino, intermediário ou espesso;

2) Enxerto de pele total, a epiderme e toda a derme, folículos pilosos, glândulas sebáceas e sudoríparas, além de plexo vascular nervoso;

3) Os retalhos, que são secções de pele compostas de epiderme, derme e tecido subcutâneo. Após serem seccionadas são deslizadas ou rodadas de forma a recobrir a área cruenta, próxima, mantendo o pedículo vásculonervoso intacto, conectando o retalho ao seu local de origem ${ }^{16-19}$.

Pela ação de produtos farmacêuticos, que interferem no mecanismo fisiopatológico da cicatrização de feridas. Apesar do grande número de drogas, pomadas, soluções no mercado, sua eficácia continua incerta $14,15,18$.

Diversos estudos sobre cicatrização mostram a evolução e a melhoria dos enxertos na reconstrução e na estétical,5,7,10. Em nossa experiência cirúrgica, observamos que pequenos ferimentos curavamse apenas com cuidados locais, com curativos e desbridamentos. Essa constatação levantou questões relativas à cicatrização conduzida, proposta original de cicatrização por segunda intenção, e à eficácia dos cuidados com feridas cutâneas sem o uso de enxertos tissulares para sua regeneração. O presente trabalho, numa seqüência dos estudos anteriores, teve como objetivos:

I) Verificar a eficácia da cura de feridas cutâneas com cicatrização conduzida;

2) Comparar os resultados macro e microscópicos da cicatrização conduzida cutânea com a resolução obtida utilizando enxertos de pele.

\section{Métodos}

Este trabalho foi realizado no Laboratório de Cirurgia Experimental, de acordo com as recomendações das Normas Internacionais de Proteção aos Animais e do Código Brasileiro de Experimentação Animal (1988) e foi aprovado pelo Comitê de Ética em Experimentação Animal da Universidade Federal de Minas Gerais ${ }^{28}$. 


\section{Figura I - Aspectos evolutivos da cicatrização conduzida e do enxerto de pele parcial realizado no dorso de coelho do grupo 2}

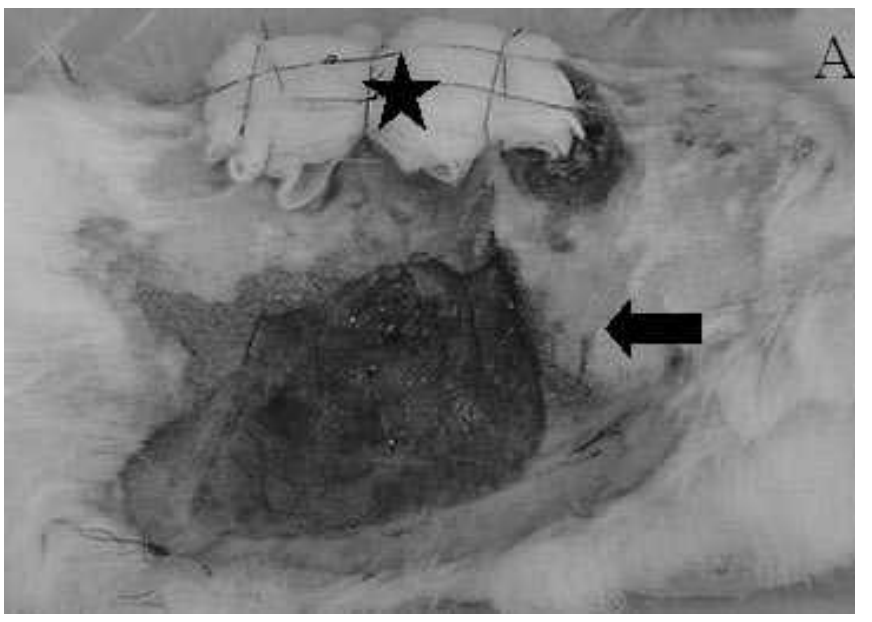

A - Área cruenta ao final da operação (seta) e curativo tie over sobre o enxerto (estrela)

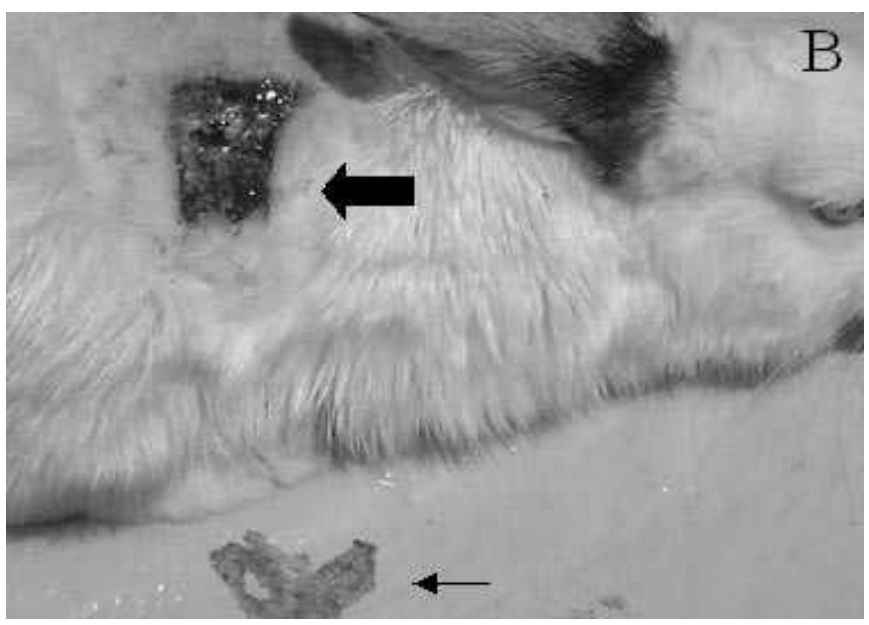

B - Área em cicatrização conduzida após sete dias (seta grossa) e crosta retirada (seta fina)
Foram estudados 20 coelhos (Oryctogalus cuniculus) da raça Califórnia, provenientes do Biotério Central da Escola de Veterinária da UFMG; três foram usados como piloto e os outros 17 foram distribuídos aleatoriamente por sorteio em dois grupos. No início do experimento, todos os coelhos estavam com 2,5 meses de idade, sexualmente maduros e com peso médio de $2088 \pm 183 \mathrm{~g}$.

Grupo I ( $n=\mid 7)$ : ressecção de dois segmentos de pele, medindo $2 \mathrm{~cm} \times 2 \mathrm{~cm}$, de cada lado do dorso e cobertura de uma das áreas cruentas com a pele do outro lado, sob a forma de enxerto de pele. Dessa maneira, cada animal apresentava em seu dorso os dois tipos de tratamento da área cruenta: subgrupo IA - cicatrização conduzida; subgrupo IB - enxerto de pele.

Grupo $2(n=7)$ : ressecção de dois segmentos de pele, medindo 5 $\mathrm{cm} \times 5 \mathrm{~cm}$, de cada lado do dorso e cobertura de uma das áreas cruentas com a pele do outro lado, sob a forma de enxerto de pele: subgrupo $2 \mathrm{~A}$ - cicatrização conduzida; subgrupo $2 \mathrm{~B}$ - enxerto de pele.

Após a cicatrização completa das feridas de todos os animais do grupo I, foram retirados aleatoriamente por sorteio sete coelhos para constituírem o grupo 2. Os sete animais deste grupo haviam sido utilizados na primeira fase da pesquisa como grupo I.

A tricotomia de todos os animais foi feita antes da anestesia. A anestesia foi induzida com injeção intramuscular na região glútea de cloridrato de quetamina a $5 \%$, na dose de $50 \mathrm{mg} / \mathrm{kg}^{20}$. Em seguida, complementou-se a anestesia com cloridrato de lidocaína a $1 \%$ com vasoconstritor, que foi injetada subcutânea nos locais da operação, antes de iniciar-se o procedimento 20,21 .

Após anti-sepsia da região dorsal, com a solução alcoólica de iodo a $1 \%$, utilizou-se marcador (plástico) com espaço vazado do tamanho da pele a ser retirada, no grupo I, com $4 \mathrm{~cm}^{2}$ de área (2 cm cada lado) e, no grupo 2, com $25 \mathrm{~cm}^{2}$ (5 cm cada lado).

As operações de todos os animais de cada grupo foram realizadas em um único dia. As amostras de biopsias para avaliação histológica da cicatrização do grupo I foram retiradas no $19^{\circ}$ dia pós-operatório, simultaneamente com a remoção dos enxertos do grupo 2. As biopsias do grupo 2 foram retiradas no $35^{\circ}$ dia pós-cirúrgico.

No grupo I, a pele foi seccionada na parte direita do dorso com bisturi, nas dimensões de $4 \mathrm{~cm}^{2}$, determinadas pelo marcador. Em seguida, foi removida e colocada em uma cuba com solução salina. Três gazes dobradas e embebidas em vaselina líquida estéril recobriram a área doadora, que permaneceu cruenta. Três carreiras de pontos verticais com fio de seda 4-0 e outra carreira dupla de fios colocada em sentido horizontal que transfixaram as gazes mantiveram-nas como tie over fixo no local. O outro segmento de pele, nas mesmas dimensões do anterior, foi retirado da parte esquerda do dorso e descartado. 0 enxerto de pele removido da parte direita e guardado em solução salina, após emagrecimento, foi fixado sobre a área cruenta da parte esquerda do dorso, por meio de seis pontos simples com fio de poliglactina 910 (Vicryl 6-0 $\left.{ }^{\circledR}\right)$, e foi colocado outro tie over fixo no local.

No terceiro dia pós-operatório, foram retirados os curativos de todos os animais dos dois grupos, utilizando solução salina, para evitar o descolamento do enxerto ou agressão aos tecidos em regeneração.

Realizou-se a mesma técnica operatória no grupo 2, com dimensões do segmento de pele retirado de $25 \mathrm{~cm}^{2}$ determinadas com 0 auxilio de um marcador.

Os animais foram contidos para a retirada de crostas que se formaram sobre a área de cicatrização conduzida; a primeira vez após sete dias e, em seguida, a cada três dias. No grupo I, apenas uma agulha $25 \times 7$ foi suficiente para a retirada das crostas, mas, no grupo 2, por serem maiores, as crostas foram removidas com o auxilio de uma tesoura de Metzenbaum. Em seguida, as feridas foram lavadas com solução salina.

De cada animal, foram colhidos três fragmentos de pele: da região de cicatrização conduzida, do enxerto de pele autógena e do dorso em região não operada. Após a retirada do fragmento de pele, os locais das biopsias foram suturados com ponto simples, utilizando fio de seda 

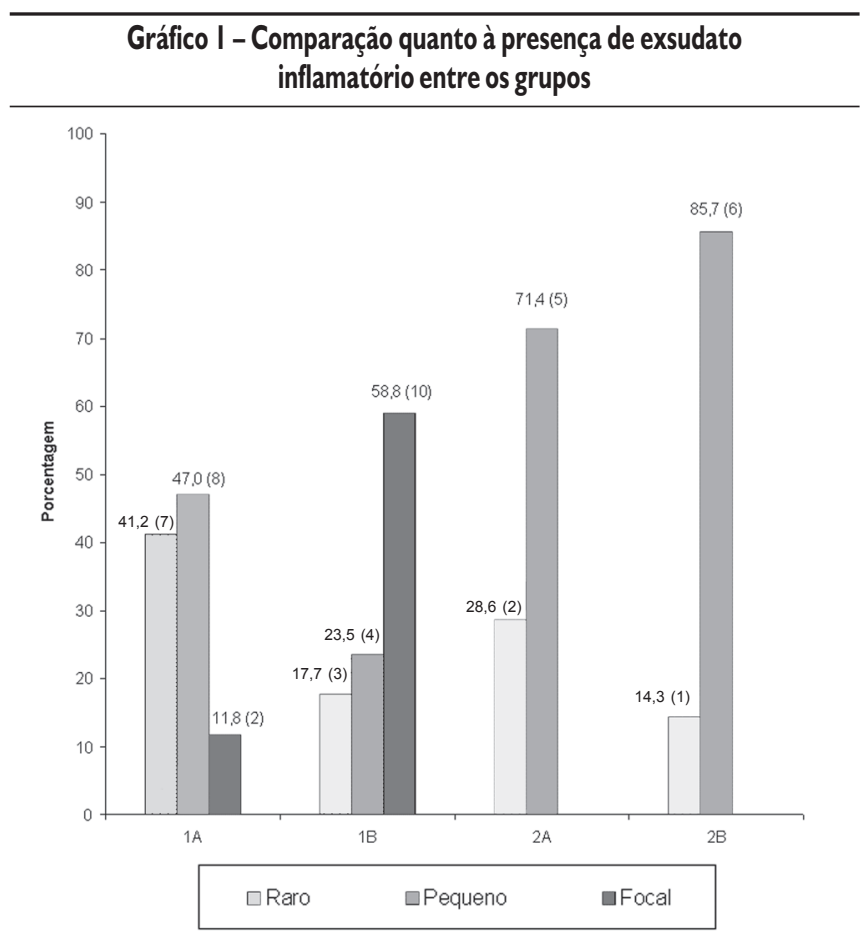

Subgrupo IA: cicatrização conduzida de pele avaliada após 19 dias

Subgrupo IB: enxerto de pele avaliado após 19 dias

Subgrupo 2A: cicatrização conduzida de pele avaliada após 35 dias

Subgrupo 2B: enxerto de pele avaliado após 35 dias

4-0. Após a fixação dos fragmentos em solução de Bouin, eles foram processados para histologia. Secções de $5 \mu \mathrm{m}$ de espessura foram montadas em lâminas de vidro e coradas com hematoxilina e eosina.

O exame histológico avaliou: medida da espessura da epiderme operada e não operada, presença de exsudato inflamatório (constituição, distribuição e intensidade), cistos epidérmicos, células gigantes e outras alterações.

Avaliaram-se comparativamente a cicatrização conduzida e o enxerto de pele parcial, utilizando a análise histopatológica nos quatro subgrupos estudados, após 19 (grupo I) e 35 (grupo 2) dias. Para a observação histológica das variáveis analisadas, os cortes foram examinados ao longo de toda a sua extensão.

A presença de exsudato inflamatório na derme e hipoderme foi considerada pelo observador e classificada em: focal (distribuição bem delimitada de mononucleares ao longo do tecido conjuntivo), pequena (presença de mononucleares e polimorfonucleares em pouca quantidade) e rara (mononucleares ocasionais dispersas no conjuntivo).

Foi utilizado o teste de Kruskal-Wallis para comparar as medidas encontradas em dez campos histológicos por animal nas avaliações de epiderme íntegra, de epiderme com cicatrização conduzida e de enxerto cutâneo. Utilizou-se o teste exato de Fisher para avaliar a diferença entre os grupos quanto ao percentual da presença de células inflamatórias, cistos epidérmicos e células gigantes. O teste de
Wilcoxon comparou os resultados entre as duas fases de tratamento (inicial e final) em relação ao peso dos animais, bem como o grupo I e o grupo 2 quanto ao tempo de cicatrização. As diferenças foram consideradas significativas para valores correspondentes a $p<0,05$.

\section{Resultados}

Todos os animais sobreviveram e recuperaram-se espontaneamente das cirurgias. O peso final dos animais foi maior que o peso no início do estudo ( $p<0,00$ I para o grupo I e $p=0,022$ para o grupo 2$)$.

Em relação à avaliação macroscópica, após 19 dias, nos coelhos do grupo I, ambas as feridas estavam cicatrizadas e, após 35 dias, no grupo 2. Não houve diferença entre os resultados dos dois tipos de tratamento nos dois grupos.

Os animais do subgrupo IA (cicatrização conduzida) cicatrizaram mais rápido do que o subgrupo IB (enxerto de pele) $(p<0,00 \mid$ ). Houve também tendência de o subgrupo $2 A$ cicatrizar em um tempo menor que o subgrupo $2 B(p<0,059)$.

O exame das cicatrizes conduzidas após 19 dias (grupo I) mostrou reepitelização completa em todos os cortes examinados, exceto em um coelho, com epitélio moderadamente espessado e células bem diferenciadas. Houve proliferação de tecido fibroso com pequenos focos de infiltrado inflamatório dentro do tecido conjuntivo. Foram ainda observados cistos epidérmicos e células gigantes esporádicas.

Em relação ao grupo 2, o aspecto histológico foi semelhante nos dois tipos de tratamento. A epiderme estava moderadamente espessada, com células bem diferenciadas, principalmente na cicatrização conduzida. Encontrou-se proliferação de tecido fibroso, com raras células inflamatórias, cistos epidérmicos e folículos pilosos.

Os coelhos operados, tanto do subgrupo da cicatrização conduzida quanto do enxerto, apresentaram espessura de epiderme maior do que a epiderme íntegra controle ( $p<0,00$ I para o grupo I e $p=0,03$ para o grupo 2). A espessura da epiderme não diferiu quando comparados cicatrização conduzida e enxerto, em ambos os grupos.

O exsudato inflamatório classificado como focal foi observado em II,8\% dos animais do subgrupo IA e em $58,9 \%$ do subgrupo IB $(p=0,025)$, não tendo sido observado no grupo 2 . O exsudato inflamatório definido como pequeno foi encontrado em maior quantidade no grupo 2 , sendo de $47 \%$ no subgrupo $|A, 7|, 4 \%$ no subgrupo $2 A$, $23,5 \%$ no subgrupo IB e $85,7 \%$ no subgrupo $2 B$. O exsudato inflamatório raro foi encontrado em $4 \mid, 2 \%$ no subgrupo $\mid A, 28,6 \%$ no subgrupo $2 \mathrm{~A}, 17,7 \%$ no subgrupo IB e I4,3\% no subgrupo $2 \mathrm{~B}$. No grupo 2, quase inexistiu.

Nos cortes histológicos, constatou-se a presença de cistos epidérmicos em $47,1 \%$ do subgrupo IA, em II,8\% do subgrupo IB $(p=0,057)$, e em $42,9 \%$ do subgrupo 2B. O subgrupo $2 A$ não apresentou cistos epidérmicos.

Foram encontradas células gigantes com ou sem corpos estranhos em seu interior apenas nos coelhos do grupo I. Foram observados numerosos folículos pilosos onde o epitélio havia se recuperado integralmente. Nos locais em que houve perda epitelial, formou-se uma cicatrização fibrosa exuberante. A fibrose também foi um achado comum que variou de intensa, jovem, para uma fibrose mais madura, e estava igualmente distribuída em todos os cortes examinados. 


\section{Discussão}

Este trabalho propõe uma nova técnica de tratamento da ferida cirúrgica, denominada cicatrização conduzida. Ela envolve o desbridamento cirúrgico com retirada de crostas da ferida em intervalos regulares de três dias, utilizando instrumental cirúrgico apropriado. A manipulação correta do tecido de granulação pode evitar infecção e alteração do tempo de cicatrização, além de mudança no aspecto final da cicatriz. A retirada das crostas favoreceu a recuperação dos tecidos envolvidos até formarem uma nova crosta, que foi removida sucessivamente, até a cura total da ferida.

Nos dois grupos, em relação ao peso dos coelhos, houve variação entre o início e o fim do experimento, comprovando que os animais se alimentaram adequadamente e que os procedimentos operatórios não provocaram uma resposta orgânica ao trauma que repercutisse em seu estado geral. Conseqüentemente, o ganho de peso e o cuidado adequado com os animais podem ter favorecido a boa cicatrização.

Do ponto de vista macroscópico, as feridas dos coelhos com cicatrização conduzida nos dois grupos sararam mais rapidamente e, apesar do uso de marcador, os cortes não saíam exatamente iguais. A contração do tecido fez com que as cicatrizes tivessem diversas conformações, tais como: estrelas, retângulos, múltiplos raios, linhas, círculos, etc. A cicatrização do enxerto quase sempre reproduziu em tamanho menor o quadrado do seu formato original. Não ocorreu contratura em cicatriz alguma e pode-se supor que o enxerto dificultou o avanço mais rápido dos processos de cicatrização a partir das bordas da pele. A ferida aberta possibilitou melhor crescimento do tecido epitelial sem obstáculos.

O tempo de cura da ferida cirúrgica dependeu de seu tamanho. Quanto maior a ferida, mais tempo levou para cicatrizar completamente, sendo a parte central mais tênue. A retirada de crostas teve por objetivo estimular a capacidade contrátil dos miofibroblastos e evitar a contratura com deformação da cicatriz.

A contração da ferida talvez seja uma das características mais importantes da cicatrização conduzida. A contração e não contratura decorreu principalmente pela ação contrátil dos miofibroblastos, células essenciais no processo de cicatrização, que abriram novos espaços de acomodaçãa $0^{21-23}$. Seu efeito de maior risco ocorre em órgãos circulares, nos quais pode provocar estenose e obstrução, além da retração nas superfícies articulares.

Vários estudos da literatura mostraram a importância da cobertura da ferida (curativos oclusivos) na reparação inicial para evitar dor, prevenir a perda de líquidos e proteger contra infecçãa ${ }^{15,21-24}$. Entretanto, esse assunto é controverso. A avaliação experimental da validade do curativo em tratamento de feridas infectadas mostrou maior redução das feridas com curativo do que naquelas sem curativos ${ }^{25}$, resultado similar ao obtido no presente trabalho. Os curativos permaneceram três dias e foram confortáveis, mantiveram as bordas laterais das feridas cirúrgicas firmes e tracionadas em direção ao centro da lesão.

Nos dois grupos, houve reepitelização completa, com proliferação de tecido fibroso e focos de infiltrado inflamatório, além de cistos epidérmicos. Essa observação comprovou a boa capacidade de recuperação do tecido epitelial, seus anexos e tecidos vizinhos. Exsudato inflamatório esteve presente em focos apenas no grupo I, por fazer parte provavelmente das fases iniciais da inflamação. Nas etapas cicatriciais subseqüentes, o exsudato inflamatório focal foi substituído pelo exsudato raro, presente no grupo 2. Da mesma maneira, as células gigantes, presentes apenas nas fases iniciais da inflamação, foram encontradas no grupo I e estiveram ausentes no grupo 2 .

No grupo I, os animais apresentaram uma maior presença de cistos epidérmicos. Esses cistos relacionam-se com a capacidade de invaginação, ou dobra da epiderme, o que parece ter ocorrido nas situações descritas.

Os estudos histológicos foram realizados em duas datas fixas, 19 e 35 dias. Essa padronização não permitiu o registro dos fenômenos cicatriciais em fases intermediárias ou posteriores a esses tempos. Essas datas foram adequadas para observar-se a cicatrização completa.

Não foi incluído um grupo com apenas área cruenta sem curativo inicial, devido ao risco de infecção, de perda de líquidos e das proteínas, de dor, além da demora na cicatrização $26,27$.

A maior vantagem da cicatrização conduzida seria evitar outras condutas cirúrgicas na pele para retirar tecidos, criando múltiplas áreas cruentas e mais cicatrizes. Essa técnica poderia ser adotada, quando houvesse indicação, principalmente em pacientes de difícil manuseio ou com alterações clínicas que requeiram operações mais rápidas.

Para obter-se melhores resultados na cicatrização conduzida, cabe estabelecer um protocolo com detalhamento dos procedimentos cirúrgicos e dos cuidados pós-operatórios. A retirada de crosta é indispensável para uma boa cicatrização.

Consideramos pertinente supor que, após mais estudos experimentais, a cicatrização conduzida tenha aplicação clínica em afecções de pele nas quais haja necessidade de ressecção de lesão, mantendo a área cruenta sem cobertura da pele, na expectativa de cura sem a necessidade de colocar enxerto ou transpor retalho.

\section{Conclusão}

A cicatrização conduzida foi eficaz na cura de feridas cutâneas dorsais em coelhos, sendo uma alternativa viável no tratamento de feridas cutâneas de tamanhos diferentes tão eficaz quanto o uso de enxerto de pele, em coelhos.

\section{Agradecimentos}

Os autores agradecem ao CNPq eà Fapemig pelos auxilios financeiros que permitiram a realização deste trabalho.

\section{Conflito de interesse: não há.}

\section{SUMmARY}

\section{Conducted healing and SKIN GRAFt for the tReatment of SKIN WOUNDS}

OBIECTNE. The presentstudy compared the treatment of skin wounds by means of conducted healing (an innovative method for treatment of secondary healing) and autogenous skin graft.

METHODS. Seventeen rabbits were submitted to removal of two skin segments, one on each side of the dorsum. The graft donor area was left as a wound for conducted healing (A) and was submitted only to debridement, local care and dressings. The skin removed from the above 
mentioned side was implanted as a graft (B) to cover the wound on the other side. Thus, each animal received the two types of treatment on its dorsum (A and B). Rabbits were divided into two groups according to size of the wounds: Group I - A and B $\left(4 \mathrm{~cm}^{2}\right)$ and Group 2-Aand B $\left(25 \mathrm{~cm}^{2}\right)$. Healing time was of 19 days for Group I and of 35 days for Group 2. The final macro- and microscopic aspects of healing were comparatively analyzed in the four subgroups. Presence of inflammatory cells, of epidermal cysts and of giant cells was assessed by histology. Data were statistically analyzed by the nomparametric Fisher, Kruskal-Wallis and Wilcoxontests.

RESULTS. No macro-ormicroscopic difference was observed between conducted healing and skin graft, although conducted healing led to a more rapid wound healing.

CONCLUSION. Conducted healingseems to be agood therapeuticoption for skin wounds in rabbits. [Rev Assoc Med Bras 2007; 53(1): 80-4]

KEY wORDS: Wound healing. Skin transplant. Debridement. Dressings.

\section{RefERÊNCIAS}

I. Arantes VN, Okawa RY, Petroianu A. Influência da ícterícia obstrutiva na cicatrização de pele e de anastomose jejunal em ratos. Rev Col Bras Cir. 1999;26:269-73.

2. Arons JA, Wainwright DJ, Jordon RE. The surgical applications and implications of cultured human epidermis. Surgery. 1992; I I I:4- I I.

3. Currie LJ, Sharpe JR, Martin R. The use of fibrin glue in skin grafts and tissue-engineered skin replacements. Plast Reconstr Surg. 200 I; 108:1713-26.

4. De Moraes AM, Annichino-Bizachi JM, Rossi ABR. Use of autologous fibrin glue in dermatologic surgery. Rev Paul Med. 1998; 1 16:1747-52.

5. Petroianu A. Silva AA., Melo MAB, Vasconcellos LS. Comparação entre cola biológica e sutura em cicatrização de pele. Rev Col Bras Cir. 2001;28:249-3.

6. Ferguson MW, Whitby DJ, Shah M, Armstrong J, SiebertJW, Longaker Mt. Scar formation. Plast Reconstr Surg. 1996;97:854-60.

7. Petroianu A. Synthesis of surgical wounds without skin suture. Plast Reconstr Surg. 1988:82:919-20.

8. Attinger CE, Bulan E, Blume PA. Surgical débridement. Clin Podiatr Med Surg. 2000; 17:599-630.

9. Falabella AF. Debridement and management of exudative wounds. Dermatol Ther. 1999:9:36-46.

10. Vasconcellos LS, Alberti LR, Petroianu A, Trivelato LP. Efeito da hidrocortisona sobre a resistência cicatricial da pele em camundongos. Rev Col Bras Cir. 200 I;28:438-43.
11. Gallico GG. Biologic skin substitutes. Clin Plast Surg. 1990; 17:519-26.

12. Billingham RE. The feasibility of altering immunogenicity of grafts. J Invest

13. Dermatol. 1976;67: 149-59.

14. Chaves DN, Petroianu A, Alberti LR, Pereira WA. Effects of thalidomide, cyclosporine and diclofenac on skin allograft survival in rabbits. Transplant Proc. 2004;36: I 0 I 8-20.

15. Nakano M, Yoshida T, Ohura T, Azami K, Senoo A, Fuse Y. Clinicopathologic studies on human epithelial autografts and allografts. Plast Reconstr Surg. 1992;90:899-909.

16. Smith DJ Jr, Thomson PD, Bolton LL, Hutchinson JJ. Microbiology and healing of the ocluded skin-graft donor site. Plast Reconst Surg. 1993;91:1094-7.

17. Oishi SN, Luce EA. The difficult scalp and skull wound. Clin Plastic Surg. 1995;22:51-59.

18. Petruzzeli GJ, Johnson JT. Skin grafts. Otolaryng Clin North Am. 1994:27:25-37.

19. Ratner D. Skin grafting. From here to there. Dermatol Clin. 1998; 16:75-90.

20. Yamamoto Y, Yokohama T, Minakawa H, Sugihara T. Use of the expanded skin flap in esthetic reconstruction of postburn deformity. J Burn Care Rehabil. 1996;7:397-40I.

21. Flecknell PA. Anaesthesia of animals for biomedical research. Br J Anaesth. 1993;71:885-94.

22. Berry D, Harding K, Stanton MR. Human wound contraction. Plast Reconst Surg. 1998; 102:124-31.

23. Carmeliet P. Mechanisms of angiogenesis and arteriogenesis. Nature Medicine 2000;6:389-95.

24. Schürch W, Thomas A, Gabbiani G. The myofibroblast. Am J Surg Pathol. 1998;22: | 41-7.

25. Rakel BA, Bermel MA, Abott LI. Split-thickness skin graft donor site care. Apppl Nurs Res. 1988; 1 1:174-82.

26. Silva AA, Júnior $\bigcirc \bigcirc$, Petroianu A. Avaliação experimental da validade do curativo em tratamento de feridas infectadas. Rev Med Minas Gerais. 1993;3:2-4.

27. Hoff C. Immoral and moral uses of animals. N Engl J Med. 1980;302: II5-8.

28. Petroianu A. Aspectos éticos na pesquisa em animais. Acta Cir Bras. 1996; 11:157-64.

Artigo recebido: 22/06/06

Aceito para publicação: 12/09/06 